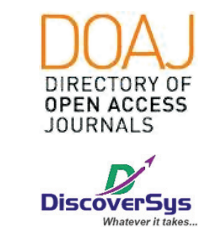

Published by DiscoverSys

\section{Profil dermatitis kontak akibat kerja pada pekerja garmen di Kota Denpasar}

\author{
Made Wardhana," Made Martina Windari, I Gusti Ayu Agung Dwi Karmila, \\ Ni Luh Putu Ratih Vibriyanti Karna, Ni Made Dwi Puspawati, \\ I Gusti Ayu Agung Praharsisni, Luh Made Mas Rusyati, Nyoman Suryawati
}

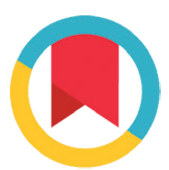

CrossMark

\title{
ABSTRACT
}

Background: The development of the garment industry in Bali is increasing as a tourism supporting industry. As a consequence the number of garment and textile companies is growing in quantity and quality. According to data in the Denpasar City, there were around 125 large garment companies employing at least 100 workers. A small garment company as a home industry is almost five hundred. The impact of the development of the garment industry requires a lot of human resources by recruiting, opening jobs both for trained and untrained workers, most of whom are casual workers, without getting attention in terms of health. This research was conducted to collect data about the pattern of skin lesions (work-related contact dermatitis) in garment workers in Denpasar City because they do not have complete and accurate data.

Methods: The method used in this study was a survey on three large garment companies in Denpasar with interviews and examinations of their skin disease patterns.

Results: Total 288 workers included in this study consisted of 105 (36.5\%) men and 183 (63.5\%) women. From 288 respondents, 74 workers (25.7\%) suffer from skin disorders related to their work. The occupational category that suffered the most was colouring workers of 30 people.

Conclusion: The pattern of skin disease in garment workers by $25.7 \%$ suffering from DKAK. Disease categories are often workers who come into contact with colour materials.

Keywords: work related contact dermatitis, garment workers, incidence, symptoms.

Cite This Article: Wardhana, M., M.M.,Windari, Karmila, I.G.A.A.D., Karna, N.L.P.R.V., Puspawati, N.M.D., Praharsisni, I.G.A.A., Rusyati, L.M.M., Suryawati, N. 2020. Profil dermatitis kontak akibat kerja pada pekerja garmen di Kota Denpasar. Intisari Sains Medis 11(2):517-522. D0I: 10.15562/ ism.v11i2.649

\section{ABSTRAK}

Latar Belakang: Perkembangan industri garment di Bali semakin meningkat sebagai salah satu industri penunjang pariwisata. Sebagai konsekuensi jumlah perusahan garmen dan tekstil semakin banyak secara kuantitas dan kualitas. Menurut data di kodya Denpasar, tercatat sekitar 125 perusahan garmen yang besar dengan memperkerjakan sedikitnya 100 orang pekerja. Perusahan garmen yang kecil sebagai industri rumah tangga hampir sebanyak lima rastusan. Dampak dari perkembangan industri garment membutuhkan banyak tenaga kerja dengan merekrut, membuka lapangan pekerjaan baik itu untuk pekerja yang terlatih maupun yang tidak terlatih, kebanyakan merupakan pekerja lepas, tanpa mendapat perhatian dari segi kesehatan. Penelitian ini dilakukan untuk mengumpulkan data tentang pola kelainaan kulit pada(DKAK) pekerja garment di Kodya Denpasar, karena belum memiliki data yang lengkap dan akurat.
Metode: Metode yang digunakan pda penelitian ini adalah survelanse, pada 3 perusahan garment yang besar di Denpasar dengan wawancara dan pemeriksaan terhadap pola penyakit kulitnya.

Hasil: Dari 288 pekerja yang di ikut sertakan dalam penelitian ini terdiri dari 105 (36,5\%) laki-laki dan 183 (63,5\%) perempuan. Dari 288 responden, sebanyak 74 pekerja $(25,7 \%)$ yang menderita kelainan kulit yang berhubungan dengan pekerjaannya. Katagori pekerjaan yang paling banyak menderita adalah pada pekerja pencelupan (coloring) sebesar 30 orang.

Simpulan: Pola penyakit kulit pada pekerja garment sebesar $25,7 \%$ menderita DKAK. Katagori penyakit sering adalah pekerja yang berhubungan kontak dengan bahan warna.
Departemen Dermatologi and Venereologi, Fakultas Kedokteran, Universitas Udayana-RSUP Sanglah Denpasar, Bali, Indonesia wardhanamade@unud.ac.id

Diterima: 21-10-2019 Disetujui: 09-07-2020 Diterbitkan: 01-08-2020
Kata kunci: dermatitis kontak kontak akibat kerja, pekerja garmen, insiden, gejala.

Cite Pasal Ini: Wardhana, M., M.M.,Windari, Karmila, I.G.A.A.D., Karna, N.L.P.R.V., Puspawati, N.M.D., Praharsisni, I.G.A.A., Rusyati, L.M.M., Suryawati, N. 2020. Profil dermatitis kontak akibat kerja pada pekerja garmen di Kota Denpasar. Intisari Sains Medis 11(2): 517-522. D0I: 10.15562/ ism.v11i2.649 


\section{PENDAHULUAN}

Industri garment adalah industri yang memproduksi pakaian jadi dan perlengkapannya. Bahan bakunya adalah kain tenun atau kain rajutan dan produknya antara lain berupa kaos. Industri ini merupakan industri padat karya, karena sebagian besar proses pengolahan bahan baku menjadi bahan jadi atau setengah jadi masih menggunakan tenaga manusia. Industri garment sebagai salah satu industri penunjang pariwisata di Bali, semakin meningkat dari tahun ke tahun. Sebagai konsekuensi jumlah perusahan garmen semakin banyak, baik secara kuantitas dan kualitas. Industri ini membuka lapangan pekerjaan baik untuk pekerja yang terlatih maupun yang tidak terlatih, kebanyakan merupakan pekerja lepas, tanpa mendapat perhatian dari segi kesehatan. ${ }^{1-3}$ Menurut data, di kodya Denpasar tercatat sekitar 179 perusahan garmen yang besar dengan memperkerjakan lebih dari 100 orang pekerja dan hampir ribuan industri rumah tangga sebagai sektor informal. Pekerja di industri ini selalu berhubungan dengan kondisi yang basah, kontak dengan bahan-bahan warna dan lama bekerja sekitar 8 jam sehari, keadaan ini sangat berisiko tinggi terjadinya dermatitis kontak atau yang lebih dikenal dermatitis kontak akibat kerja (DKAK) atau occupatioanal contact dermatitis (OCD).

Penyakit kulit akibat kerja merupakan salah satu penyakit akibat kerja (occupational disease) atau lingkungan kerja yang banyak terjadi pada masyarakat, terutama masyarakat pekerja. Dermatitis kontak akibat kerja (DKAK) adalah dermatitis atau keradangan yang disebabkan terpaparnya kulit dengan bahan dari luar yang bersifat iritan atau alergen, paparan bahan-bahan zat warna, bahan pangawet dan bahan kimia lainnya Gambaran klinis dan perjalanan penyakit dermatitis kontak akibat kerja sangat bervariasi tergantung pada berbagai faktor internal maupun eksternal, dapat akut maupun kronis. ${ }^{4}$

Mathias et al. ${ }^{5}$ telah memberikan kretirea untuk pedoman diagnosis DKAK dengan tujuh pertanyaan cukup untuk mengetahui penyebab serta hal yang memperburuk dermatitis kontak akibat kerja yaitu: (1) Apakah gambaran klinis sesuai dengan dermatitis kontak?, (2) Apakah tempat kerja terpapar oleh alergen dan iritan yang potensial?, (3) Apakah distribusi anatomis dari erupsi sesuai dengan paparan pekerjaan?, (4) Apakah hubungan antara paparan dengan onset konsisten dengan dermatitis kontak? (5) Apakah paparan diluar pekerjaan sudah dieksklusi sebagai penyebab?, (6) Apakah dermatitis berkembang jauh sebelum paparan pekerjaan terhadap iritan dan alergen yang dicurigai? (7) Apakah tes tempel dan tes profokasi mengidentifikasi kemungkinan penyebab?

Penelitian tentang angka kejadian DKAK pada pekerja garment ini dilatar belakangi oleh adanya faktor risiko terjadinya penyakit ini pada pekerja garment berupa bahan kimia bahan pengawet dalam kain, bahan warna dan kondisi yang basah. Dari bahan baku menjadi produk akhir mengalami suatu proses yang panjang, dari pemotongan kain (mendisain), pencelupan (sablon), penjahitan dan terakhir mengepakan (packing). Para pekerja umumnya bekerja pada spesifikasi masing-masing. Faktor risiko lainnya adalah bila pekerja memang sudah mempunyai riwayat alergi sebelumnya, faktor keluarga, lama jam kerja, mempergunakan alat pelindung diri(APD). ${ }^{6}$

Sampai saat ini kita belum mengetahui prevalensi, variasi klinis dan fartor yang mempengaruhi dematitis kontak akibat kerja pada pekerja garment, oleh karena itu kami ingin melakukan penelitian awal dan perusahan garment yang kami teliti sebanyak 4 perusahan yang cukup besar dan terkenal yang memperkerjakan lebih dari 100 pekerja setiap perusahan serta telah memiliki klinik dalam perusahan tersebut. $^{7}$

Tujuan dari penelitian ini adalah untuk mengetahui prevalensi DKAK pada pekerja garmen, variasi klinis, faktor risiko DKAK, dan beberapa kasus dilakukan tes tempel.

\section{METODE PENELITIAN}

Penelitian dilakukan secara cross-sectional study 288 pekerja garmen di empat perusahan garmen yang besar di kodya Denpasar. Wawancara dan pemeriksaan klinis terhadap penyakit kulit yang muncul sejak saat bekerja. Wawancara dilakukan secara terstruktur mengenai tipe pekerjaan dan bahan yang digunakan tempat para pekerja sering kontak. Pekerja dikelompokan dalam tiga kelompok, sebagai berikut: (1) Tahap persiapan, yaitu pekerja yang bekerja; Cleaning, washing, desizing and singeing, (2) Tahap processing (pengolahan) yaitu pekerja yang melakukan; penjahitan, pencelupan, (3) Tahap Finishing Process, yang bekerja, merapikan, setrika, mengepak produk yang sudah jadi siap untuk dipasarkan. ${ }^{7}$

Pekerja pada tahap 1 dan 3 dikategorikan oleh peneliti kedalam kategori A, dan pekerja pada tahap 2 dikategorikan kedalam kategori B, para pekerja ini yang langsung berhubungan dengan pewarnaan dan basah. Setiap pekerja diminta waktunya untuk wawancara pada saat istirahat tentang riwayat keluarga, lama kerja, riwayat penyakit penykit atopi dan dilakukan pemerikasaan fisik. Bila ditemukan kasus penyakit kulit diberikan pengobatan. Tes 
tempel dilakukan pada pasien yang bersedia untuk dilakukan dengan tidak membebani biaya, dan dikirim ke Poliklinik Kulit RS Sanglah, penelitian ini dilakukan selama 3 bulan. Data-data yang sudah terkumpul di analisis secara diskriptif.

\section{HASIL PENELITIAN}

Penelitian ini dilakukan di 4 industri garment terbesar di Kodya Denpasar. Total subjek atau responden yang diteliti sebesar 288 orang. Dari 288 orang pekerja ternyata dijumpai 74 pekerja (25.7\%) menderita DKAK, pekerja garmen yang kebanyakan perempuan $(63.5 \%)$ dibandingkan dengan laki-laki (36.5\%) (Tabel 1).

Pada tabel 2, menggambarkan 74 pekerja dengan dengan DKAK dan katagori pekerjaan. 31 (41,9\%) pada kategori A, dan $43(58,1 \%)$ pada kategori B. Dikatakan akut, bila lesinya bersifat eksudatif, dikatakan kronis bila sudah terjadi plak yang hiperkeratosis (penebalan kulit). Riwayat keluarga 15 (20,3\%) menytakan ada. Riwayat atopi 20 (27\%) mengatakan mempunyai atopi, seperti dermatitis atopi, asma dan rinitis atopik. Lamanya kerja paling banyak, telah bekerja selama 3 tahun sebanya 27 (36,5\%) dan pekerja $47(63,5 \%)$ lebih dari 3 tahun. Lima puluh delapan orang $(78,4 \%)$ tidak pernah mengtakan tidak memakai alat pelindung diri (APD)

Dermatitis akibat kerja kami golongkan tipe iritan dan tipe alergi. Didiagnosis dermatitis kontak iritan (DKI) bila: disebabkan iritan primer, kontak pertama, semua orang, eritema, klinis berupa vesikel/bula, batas tegas. Dermaratitis kontak alergi (DKA) bila disebabkan oleh alergen/sensitizer, kontak berulang, orang yang sudah alergi, rasa gatal yang dominan, lesi lebih bersifat polimorfi. ${ }^{6}$

\section{Hasil patch test}

Pekerja yang menderita DKAK, 11 orang yang bersedia dilakukan patch test. Patch test dilakukan dengan mempergunakan produk dari European standard, dengan 20 allergens. Setiap pasien yang dites bisa

\section{Tabel 1 Distribusi karateristik umum 288 pekerja garmen}

\begin{tabular}{|c|c|c|c|}
\hline Karateristik Umum & $\begin{array}{c}\text { Laki-laki } \\
\mathrm{n}=105(36,5 \%)\end{array}$ & $\begin{array}{c}\text { Perempuan } \\
n=183(63,5 \%)\end{array}$ & Total \\
\hline \multicolumn{4}{|l|}{ Usia (tahun) } \\
\hline$<17$ & $17(5,9 \%)$ & $29(10 \%)$ & $46(15,9 \%)$ \\
\hline $17-30$ & $45(15,6 \%)$ & $61(21,1 \%)$ & $106(36,7 \%)$ \\
\hline$>30-50$ & $32(11,3 \%)$ & $72(25 \%)$ & $104(36,3 \%)$ \\
\hline$>50$ & $11(3,8 \%)$ & $21(7,3 \%)$ & $32(11,1 \%)$ \\
\hline \multicolumn{4}{|l|}{ Daerah asal } \\
\hline Bali & $61(21,2 \%)$ & $95(32,9 \%)$ & $156(54,1 \%)$ \\
\hline Jawa & $20(6,9 \%)$ & $48(16,6 \%)$ & $68(23,6 \%)$ \\
\hline Lombok & $17(5,9 \%)$ & $32(11,1 \%)$ & $49(17,1 \%)$ \\
\hline Lainnya & $7(2,5 \%)$ & $8(2,7 \%)$ & $15(5,2 \%)$ \\
\hline \multicolumn{4}{|l|}{ Lama kerja } \\
\hline$<1$ tahun & $22(7,7 \%)$ & $51(17,7 \%)$ & $73(25,4 \%)$ \\
\hline $1-3$ tahun & $50(17,3 \%)$ & $78(27,1 \%)$ & $128(43,4 \%)$ \\
\hline$>3$ tahun & $33(11,4 \%)$ & $54(18,7 \%)$ & $87(30,2 \%)$ \\
\hline \multicolumn{4}{|l|}{ Tingkat pendidikan } \\
\hline Tidak sekolah & $17(5,9 \%)$ & $32(11,1 \%)$ & $49(17 \%)$ \\
\hline Sekolah Menengah Atas (SMA) & $29(10,1 \%)$ & $61(21,2 \%)$ & $90(31,3 \%)$ \\
\hline Kuliah & $52(18,1 \%)$ & $81(28,2 \%)$ & $133(45,3 \%)$ \\
\hline Sarjana & $7(2,2 \%)$ & $9(3,2 \%)$ & $15(5,4 \%)$ \\
\hline \multicolumn{4}{|l|}{ Kategori pekerjaan } \\
\hline A & $50(17,4 \%)$ & $83(29,8 \%)$ & $133(46.2 \%)$ \\
\hline $\mathrm{B}$ & $55(74,4 \%)$ & $100(34,4 \%)$ & $155(53.8 \%)$ \\
\hline \multicolumn{4}{|l|}{ Status DKAK } \\
\hline $\mathrm{Ya}$ & $31(10,8 \%)$ & $43(14,9 \%)$ & $74(25,7 \%)$ \\
\hline Tidak & $74(25,7 \%)$ & $140(48,6 \%)$ & $214(74,3 \%)$ \\
\hline
\end{tabular}


Table 2 Hubungan 74 dengan DKAK dan katagori pekerjaan

\begin{tabular}{|c|c|c|c|c|c|}
\hline & \multicolumn{4}{|c|}{ Katagori pekerjaan } & \multirow{2}{*}{$\begin{array}{l}\text { Jumlah (\%) } \\
74(100 \%)\end{array}$} \\
\hline & \multicolumn{2}{|c|}{$\begin{array}{c}A \\
31(41,9 \%)\end{array}$} & \multicolumn{2}{|c|}{$\begin{array}{c}\text { B } \\
43(58,1 \%)\end{array}$} & \\
\hline \multicolumn{6}{|l|}{ Kronisitas } \\
\hline Akut & \multicolumn{2}{|c|}{$21(28,5 \%)$} & \multicolumn{2}{|c|}{$34(45,9 \%)$} & $55(74,4 \%)$ \\
\hline Kronis & \multicolumn{2}{|c|}{$10(13,5 \%)$} & \multicolumn{2}{|c|}{$9(12,1 \%)$} & $19(25,6 \%)$ \\
\hline \multicolumn{6}{|l|}{ Riwayat keluarga } \\
\hline Ya & \multicolumn{2}{|c|}{$2(2,7 \%)$} & \multicolumn{2}{|c|}{$13(17,5 \%)$} & $15(20,2 \%)$ \\
\hline Tidak & \multicolumn{2}{|c|}{$29(39,1 \%)$} & \multicolumn{2}{|c|}{$31(41,8 \%)$} & $59(79,8 \%)$ \\
\hline \multicolumn{6}{|l|}{ Riwayat atopik } \\
\hline Ya & \multicolumn{2}{|c|}{$6(8,1 \%)$} & \multicolumn{2}{|c|}{$14(19 \%)$} & $20(27,1 \%)$ \\
\hline Tidak & \multicolumn{2}{|c|}{$25(33,7 \%)$} & \multicolumn{2}{|c|}{$29(39,2 \%)$} & $54(72,9 \%)$ \\
\hline \multicolumn{6}{|l|}{ Lama Kerja } \\
\hline$<3$ & \multicolumn{2}{|c|}{$12(16,2 \%)$} & \multicolumn{2}{|c|}{$15(20,3 \%)$} & $27(36,5 \%)$ \\
\hline$>3$ & \multicolumn{2}{|c|}{$19(25,7 \%)$} & \multicolumn{2}{|c|}{$28(37,8 \%)$} & $47(63,5 \%)$ \\
\hline \multicolumn{6}{|l|}{$\begin{array}{l}\text { Penggunaan alat pelindung diri } \\
\text { selama bekerja }\end{array}$} \\
\hline Tidak pedrnah/kadan-kadang & \multicolumn{2}{|c|}{$24(32,4 \%)$} & \multicolumn{2}{|c|}{$34(46 \%)$} & $58(78,4 \%)$ \\
\hline Selalu memakai & \multicolumn{2}{|c|}{$7(9,5 \%)$} & \multicolumn{2}{|c|}{$9(12,1 \%)$} & $16(21,6 \%)$ \\
\hline Tipe Dermatitis Kontak & DKI & DKA & DKI & DKA & \\
\hline Tangan/Lengan bawah & $11(14,8 \%)$ & $9(12,1 \%)$ & $16(21,7 \%)$ & $8(10,8 \%)$ & $74(100 \%)$ \\
\hline Wajah/leher & $9(12,1 \%)$ & $3(4,1 \%)$ & $7(9,5 \%)$ & $4(5,4 \%)$ & \\
\hline \multirow[t]{2}{*}{ Tungkai bawah } & $2(2,7 \%)$ & $1(1,4 \%)$ & $2(2,7 \%)$ & $2(2,7 \%)$ & \\
\hline & $22(29,7 \%)$ & $13(17,5 \%)$ & $25(33,7 \%)$ & $14(18,9 \%)$ & \\
\hline
\end{tabular}

Table 3 Hasil tes tempel pada 11 pasien dengan DKAK

\begin{tabular}{lcc}
\hline & Kategori Pekerjaan A & Kategori pekerjaan B \\
\hline Potassiumbichromat (0.5\% Pet) & $2(18,1 \%)$ & $5(45,5 \%)$ \\
Parabens mix (3X5\% Pet) & $3(27,3 \%)$ & $6(54,5 \%)$ \\
Formaldehyde (1\% Aq) & $5(45,5 \%)$ & $2(18,1 \%)$ \\
Fragracance Mix (1\% Aq) & $1(9,1 \%)$ & $2(18,1 \%)$ \\
Para Phenylediamine Dihydrochloride (PPD) & $2(18,1 \%)$ & $3(27,3 \%)$ \\
Thiuram Mix (1\% Pet) & $5(45,5 \%)$ & $2(18,1 \%)$ \\
Cobalt Chlorid (0,5\% Pet) & $3(27,3 \%)$ & $1(9,1 \%)$ \\
Isopropyl Phenyl 4 (Black Rubber mix) & - & - \\
\hline
\end{tabular}

memberikan lebih dari satu alergen yang positive. Alergen yng paling banyak memberikan hasil positip adalah; Parabens mix, Potassiumbichromat, Formaldehyde, Para Phenylediamine Dihydrochloride (PPD) (Tabel 3).

\section{PEMBAHASAN}

Dari 288 pekerja garmen yang direkrut terdiri dari laki-laki 105 (36,5\%), dan Perempuan $183(63,5 \%)$, dari semua pekerja pekerja $74(25,7 \%)$ orang menderita DKAK, $31(10,8 \%)$ laki-laki dan
43 (14,9\%) perempuan. Industri garmen lebih banyak meperkerjakan tenaga perempuan sesuai dengan bidangnya keterampilannya, seperti surve oleh Soni et al. menjumpai 29\% terjadi DKAK pada pekerja pabrik tekstil, dan lebih banyak pada perempuan, dan usia pekerja berkisar antara 19 tahun - 46 tahun. $^{8}$

Lama kerja yang paling sedikit adalah 6 bulan dan yang paling lama adalah 18 tahun 5 bulan. Katagori pekerjaannya terdiri dari katagori A sebesar 133 (46,29\%), terdiri dari 50 laki-laki dan 83 perempuan dan kategori B sebanyak 155 (53,8\%), 
terdiri dari 55 laki-laki dan 100 perempuan. Pekerja yang menderita DKAK. Berdasarkan kategori pekerjaannya, kategori A $31(41,9 \%)$ pekerja, dan kategori B $43(58,1 \%)$ pekerja. Katagori B termasuk pekerja yang selslu berhubungan dengan bahan kimia pada kain, sablon dan printing dan dalam kondisi basah. Hal ini mungkin sehubungan dengan lama kerja para pekerja yang rata-rata diatas 5 tahun. Hal yang sama juga oleh penelitian Maiphetlho et al. ${ }^{9}$

Jumlah penderita kronis lebih banyak daripada akut, yaitu 13 orang, yang brarti merupakan 61,90\% dari keseluruhan kasus, menderita akut 21 pada kategosi A, 34 pada kategori B. Kronis 20 pada A dan 9 pada B, dari 74, 2 memiliki penyakit yang sama pada keluarganya pada A, dan 13 pada B, dan 29 tidak memilik riwayat keluarga pada A dan 31 pada B..$^{10}$

DKAK, berdasarkan katagori pekerjaan (A dan B) dan hubungannya dengan tipe DKAK, ICD, $47(63,5 \%)$ dan ACD, 27(36,5\%) serta hubungannya dengan lokasi lesi kulit. Tampak pada tabel 3 pekerja katagori B paling banyak menderita dermatitis kontak iritan, dan pada katagori A lebih banyak dermatitis kontak alergi. Lokasi lesi paling banyak pada tangan/lengan bawah. Pada semua penelitian DKAK dijumpai akut lebih banyak, karena iritan paling banyak penybabnya. ${ }^{11,12}$

Dari 74, 6 memiliki penyakit atopi lainnya pada A, dan 14 pada B, dan 25 tidak memilik penyakit atopi lainnya pada kategori A dan 29 pada B. Dari 21 penderita dermatitis kontak yang didapatkan pada pekerja garment ini, 6 orang $(28,57 \%)$ memiliki riwayat alergi. Riwayat alergi ini mempermudah terjadinya dermatitis kontak karena faktor individu yang lebih succeptibel.Mengenai lama bekerja $<3$ tahun 12 pada A,15 pada B. Lebih dari 3 tahun 19 pada A, dan 28 pada B. Pada dermatitis atopi dikatakan lebih rentan terhadap bahan iritan dan pada orang yang menderita penyakit atopik lainnynya dikatakan lebih sensitif terhadap kontak dengan bahan iritan. ${ }^{13,14}$

Mengenai lokasi DKAK, tidak hanya pada tangan dan lengan saja tapi juga pada leher dan tungkai bawah, hal ini dimungkinkan karena alergen maupun iritan pada kain dapat mengenai bagian tubuh yang lain. Bahan baku utama yang dipakai di garment ini adalah kain. Kainkain tersebut disimpan dalam bentuk gulungangulungan besar, sehingga memungkinkan adanya akumulasi debu. Debu merupakan salah satu faktor yang bisa menyebabkan kejadian dermatitis kontak. Selain itu, beberapa orang mempunyai alergi terhadap jenis kain tertentu. Debu juga merupakan faktor resiko terjadinya infeksi saluran nafas atas (ISPA). Bahan pewarna, sebelum diotong, kain-kain tersebut telah diberi motif dengan berbagai jenis bentuk dan warna. Bahan pengawet, beberapa jenis bahan pengawet juga sebagai alergen dan iritan. ${ }^{15,16}$

Cara terbaik untuk mencegah dermatitis kontak akibat kerja adalah dengan menghindari kontak dengan zat penyebab alergi dan iritasi, jika tidak bisa menghindarinya, ada beberapa cara untuk mengurangi risiko terkena dermatitis kontak, yaitu: mempergunakan alat pelindung diri (APD), membersihkan kulit setelah terpapar zat yang menimbulkan iritasi atau alergi. Gunakan pelembap, hal ini bertujuan untuk memperbaiki kondisi lapisan terluar kulit, sehingga kulit terlindung dari zat penyebab alergi atau iritasi. ${ }^{17} \mathrm{Pada}$ penelitian ini, penggunaan APD sangat kecil, tidak pernah menggunakan APD (24 orang) pada kelompok pekerja A dan 34 orang pada kelompok pekerja B. Hanya 7 pekerja selalu menggunakan APD pada kategori A, dan hanya 9 pekerja selalu menggunakan APD pada kategori B, hal sama pernyataan dari Sultan et al. banyak pekerja yang belum memahami pentingnya pemakaian APD untuk mehindari terjatinya DKAK. ${ }^{17}$

Hasil tes tempel, pekerja yang menderita DKAK, 11 orang yang bersedia dilakukan patch test. Tabel 3 adalah hasil Patch test pada 11 pekerja. Alergen yang paling banyak memberi hasil positif adalah Potassiumbichromat. Sesuai dengan penelitian $\mathrm{Yu}$ et al. alergen yng paling banyak memberikan hasil positip adalah; Parabens mix, Potassiumbichromat, Formaldehyde, Para Phenylediamine Dihydrochloride (PPD). ${ }^{18}$ Hal ini juga sama dengan penelitian Dita et al. epoxi resin, Potassiumbichromat, Formaldehyde merupakan bahan pengawet kain. ${ }^{19}$ Tes tempel dapat dipakai untuk memperoleh penyebab terjadinya DKAK.

\section{SIMPULAN}

Dari penelitian ini, sebanyak 288 pekerja garment 74 orang $(25,7 \%)$ menderita DKAK, hampir semua pekerja tidak memakai pelindung. Sebelas pekerja dengan DKAK dilakukan patch test dengan Parabens mix, Potassiumbichromat, dan Formaldehyde memberikan hasil yang positif.

Dengan edukasi dengan mempergunakan alat pelindung diri maka dari 74 pekerja, dengan konsisten memakai alat pelindung diri maka 46 pekerja $(62,16 \%)$ mengalami perbaikan.

\section{KONFLIK KEPENTINGAN}

Peneliti menyatakan tidak terdapat konflik kepentingan terkait publikasi dari artikel ini. 


\section{ETIKA DALAM PENELITIAN}

Penelitian ini telah mendapatkan ijin dari Komite Etik Fakultas Kedokteran Universitas Udayana/ RSUP Sanglah Denpasar, seluruh sampel dalam penelitian ini telah mendapatkan suatu inform consent untuk menjadi sampel dalam peneltian serta menandatangani lembar persetujuan untuk dilakukan suatu uji tes tempel.

\section{DAFTAR PUSTAKA}

1. Shihab M, Jain SK. The Preparedness of The Indonesian Garment Exporters in The Post-Mfa Scenario: An Analysis from the Survey. Gadjah Mada International Journal of Business. 2004;6(3):383-404.

2. Muhardi M. Sektor Pariwisata dan Industri yang Relevan Serta Jasa Pendukungnya (Studi Pemetaan di Kecamatan Gantung Kabupaten Belitung Timur); 2012.

3. Devaraja TA. Indian Textile and Garment Industry-An Overview. Department of Commerce Post Graduate Centre University of Mysore Hassan: India; 2011.

4. Peate WF. Occupational Skin Disease. Am Fam Physician. 2002;66:1025-32.

5. Toby MG, Cincinnat M. Contact dermatitis and workers' compensation: Criteria for establishing occupational causation and aggravation Journal of the American Academy of Dermatology. 2000;20(5):842-848.

6. Richard PU, Marcela R. Diagnosis and Management of Contact Dermatitis. Am Fam Physician. 2010;82(3): 249-255.

7. Lerato M. Contact Dermatitis in The Textile Industry. Current Allergy \& Clinical Immunology. 2007;20(1):28-35.

8 Paolo L, Luca S, Antonio C, et al. Clinical and epidemiological features of textile contact dermatitis: an Italian multicentre study. Contact Dermatitis. 2014;70:344-350.

9. Tessa K, Jennifer C, Amanda N. Incidence and prevalence rates for occupational contact dermatitis in an Australian suburban area. Contact Dermatitis. 2005:52:254-259.
10. Wigger-AP, Elsner P. Occupational Contact Dermatitis in the Textile Industry. Curr Probl Dermatol. 2003;31: 117-122.

11. Cecilia S, Malin E, Laura M. Textile Contact Dermatitis: How Fabrics Can Induce Dermatitis. Curr Treat Options Allergy. 2019;6:103-111.

12. Yu-Xin C, Hai-Yan C, Lin-Feng L. Prevalence and risk factors of contact dermatitis among clothing manufacturing employees in Beijing: A cross-sectional study. Medicine. 2017;96:12(e6356).

13. Megha B, Rajesh KY. Occupational Health Hazards and Awareness of Occupational Safety Among Workers Of Textile Dyeing Industries In Jaipur, India. SGVU Int J Env Sci Technol. 2008;2(2):30-38.

14. Fuentes CM, Blanco CD, Herrero G. Contact allergic dermatitis due to textile fabrics. Alergol Inmunol Clin. 2000;15:88-92.

15. Edita NS, Beatrice M, Aistė A, et al. Garment industry in Lithuania: a study of self-reported dermatological problems. Acta Medica Lituanica. 2015;22(3):129-135.

16. Gasperini G, Farli M, Lombardi P, Sertoli A. Contact Dermatitis in the Textile and Garment Industry. Current Topics in Contact Dermatitis. 2000;12:326-329.

17. Sultan TA. Prevention of Occupational Contact Dermatitis. J Ergonomics. 2016;6(3):1-3.

18. Yu-Xin C, Bing-AG, Hai-Yan C, and Lin-Feng L. Survey of Occupational Allergic Contact Dermatitis and Patch Test among Clothing Employees in Beijing. BioMed Research International. 2017;13:1-10.

19. Dita MA, Endang S, Achadiyani S. Etiology of Allergic Contact Dermatitis based on Patch Test. AMJ. 2017;4(4): 541-5.

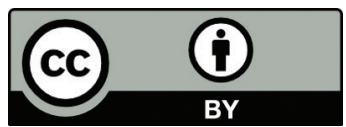

This work is licensed under a Creative Commons Attribution 